\title{
UNESCO AND AFRICAN HISTORIOGRAPHY
}

\author{
Jan Vansina \\ University of Wisconsin-Madison
}

Unesco's General History of Africa (henceforth GHA) is now nearing completion-seven out of the eight volumes having been published in English, at least-and the time is ripe to draw attention to its role in the historiography of African history, a role very different from that played by the Cambridge History of Africa with which it is often compared. ${ }^{1}$ In certain ways the Unesco project has been a unique venture, and not just in African history but, in general, because it broke with old established practice. The work was not guided by one or two editors but by a large committee. History-writing by committee seemed not only distasteful but impossible to achieve to many, both because of the practical difficulties involved and because it seemed incredible that so many editors could agree on a common text, without falling into sheer banality. Now that the volumes are out, readers can judge for themselves. Many among them actually wonder how exactly these volumes and chapters were created. Because I have been an active member of the committee since its creation in 1971 and of its bureau since 1983, I can provide a general answer to this question. But the time has also come to draw attention to the records generated by this project. Future researchers will find a huge mass of papers involving hundreds of historians of Africa that touch on practically all aspects of Africa's historiography between $\mathrm{ca} .1965$ and today. ${ }^{2}$

\section{II}

\section{The Beginning}

At its founding meeting in 1963 the Organisation of African Unity asked Unesco to create a general history of Africa to replace the books then used in African schools, which were castigated for teaching nonsense along the lines of "nos ancêtres les gaulois" or were still praising how civilization was brought to the continent by the colonial powers. It was felt that the 'real' history of Africa still remained to be told. The links between pan-African nationalism and this project are therefore close. At the same time the request recognized the political importance of historians to an unprecedented degree, unprecedented at least since the halcyon days of Michelet. We do not know precisely who inspired this unusual request. I have been told that the inspiration came from French-speaking quarters who were more attentive to cultural matters than others ${ }^{3}$ and from Arabic-speaking milieux in North Africa. H.E. Muhammad el Fassi from Morocco, M. Glele from Dahomey (Benin) at Unesco, and J. Devisse from France have been mentioned in this context.

History in Africa 20 (1993), 337-52. 
The mandate was without precedent, yet the following year the general conference of Unesco, i.e., the body of official delegates from member countries, directed the agency to carry it out. Work began in 1965, when Unesco officials, in consultation with some historians (whom exactly, I do not know), began to consider what was to be done and how. During a first period from 1965 to 1969 the agency contacted universities in Africa and outside. Thus while I was at Lovanium in 1967 I received a questionnaire asking for a list of the historians of Africa and a synopsis of the research they were conducting. By such means Unesco headquarters built up a file identifying most historians working in the field. At the same time its officials arranged for the existing International Council on Archives to publish guides to the African holdings of the major public and some private archives in Europe. The first volume appeared in $1971 . .^{4}$ During this period as well Unesco began to work out the quandaries involved in the task of writing this history. The direction would have to be in the hands of outside experts, not officials of the institution, yet Unesco was responsible. Hitherto Unesco had worked with small teams of academic consultant 'experts' when necessary. In such cases experts represented only themselves, and were in no way spokespersons for their country. Such teams produced reports which the agency could or could not publish. The novelty in this case was the size of the task, the size of the committee, its independence, and its sole responsibility for, and control of, the content of the projected history.

Moreover, a rival enterprise was also well underway at this time. This was The Cambridge History of Africa (henceforth CHA). The Cambridge University Press had proposed this project as early as the late 1950 s. ${ }^{5}$ Roland Oliver and John D. Fage, who had been approached, felt then that it was premature. But the idea was taken up again and in 1966 Oliver and Fage undertook the task, one year after Unesco had accepted its brief. Contacts between the editors of the Cambridge History and Unesco occurred probably at that time and J.D. Fage eventually agreed to be a member of the agency's committee. But the projects went ahead in their separate ways, so that eventually two eight-volume histories of Africa were published. The clear contrast in conception and execution between these two monumental works will no doubt fascinate historiographers for many years to come.

When the agency felt that it had gone as far as it could on its own, Unesco called two successive meetings of African historians as consultants in Paris (1969) and Addis Ababa (1970), to gain support for the project, discuss its realization, assess its needs, and clarify its goals. The agency then decided to entrust the task of writing the GHA to a committee of 39 members, one per country, from countries located in all parts of the world, two-thirds of whom were to be African, all working in their personal capacities (i.e., not representing their countries). The composition of the committee reminds us that Unesco is an international association of nation-states, a fact that has inevitably left its mark on GHA. Once 28 prospective members of the committee had accepted the appointment, the committee was convened to Paris in 1971 to launch the project. ${ }^{6}$ 


\section{Founding the Project: Paris 1971}

The 1971 meeting in Paris was the most crucial one in the history of the project. It elaborated the project in detail and developed the machinery to achieve it. At the outset a small subcommittee was set up to negotiate statutes that described the exact relations between Unesco and the editorial committee. ${ }^{7}$ The committee was autonomous in that it retained absolute control over the production of the texts of all works that were to result from its activities, including the appointment of authors, while Unesco kept control of the finances, the secretariat, and publication. The proposed statutes were then discussed by the whole committee during a sometimes acrimonious debate between Unesco officials and various committee members. But agreement was reached and amended statutes were adopted by the whole committee. The structure set up in 1971 proved to be quite serviceable until 1989, except when it came to matters of publication and publishers' contracts, which have led to numerous tussles between the committee and the agency.

It was further proposed that the committee would meet every two years and would start each session by electing an executive committee called a Bureau. This consisted of a president, acting for the committee during the biennium, six vice-presidents, and a rapporteur (committee reporter). Five of these people had to be Africans. The Bureau's task was to direct the project between committee meetings every six months or so. Between meetings of the Bureau, the rapporteur was to remain in contact with the head of the Unesco secretariat. Much of the credit for the smooth cooperation between Unesco and the committee that followed must go to $\mathrm{M}$. Glele, acting for Unesco until 1989, and J. Devisse of the Universite de Paris I, who was elected rapporteur in 1971 and has been re-elected ever since. Together they have acted as a driving force for most of the duration of the project. ${ }^{8}$ The subcommittee also developed the practical rules for generating and editing the texts. They worked out the respective roles of authors, volume directors, and the committee itself.

Contracts with the authors in effect bought texts from them. Authors were to deliver a draft, then make the revisions that might be required, and were set deadlines for delivery. Drafts could be accepted, rejected altogether, or used either as a basis for development by other authors, or as "material contributed" when another author was asked to write a new basic draft. When the committee accepted a revised draft, the authors could, if they so wished, refuse to have the final product appear under their names.

The directors of volumes were to be appointed by the committee. The statutes amended in the general session foresaw that they would be Africans, professional historians, hail from different countries representing all parts of Africa, and be members of the committee itself. Their task was not to edit and hence they are not labeled "editor" on the cover of the volume they directed. Editing was the job of the committee as a whole. The main role of the directors was to remain in contact with the twenty to thirty authors who were writ- 
ing chapters for the volume they directed, transmit the observations of the committee to them, receive their drafts via Unesco, alter them until they could approve of them, and transmit them to the conmmittee for its consideration. They also played a major role in gathering the appropriate illustrations for the volume,${ }^{10}$ did the final proofreading of the approved draft, and in practice often wrote the first or last chapters providing a general overview and interpretation of the contents of their volume. Directors were also asked by the committee to summarize their volumes for paperback editions and to submit this text to the committee for approval, modification, or rejection. ${ }^{11}$

The committee-as-editor decided on the structure and content of each volume; chose authors or contributors; accepted, modified or rejected chapters approved by the volume director; and adopted or rejected all amendments proposed in writing by individual members. All drafts of proposed chapters were sent to all members, who were invited to comment or to seek comments from specialists in the subject matter under discussion. As it turned out in practice, detailed written comments for each chapter were usually sent in by four or five members. A rapporteur was designated by the committee for each volume, whose task it was to collate and present all comments made about every chapter and provide a summary opinion of the situation in a progress report presented at every meeting of the committee where this volume was discussed. Rapporteurs also followed all proposals made concerning that volume and subsequently reported on any action taken with regard to such proposals. The rapporteur therefore acted as a control independent of the volume director. Yet, despite the implicit potential for friction here, in most cases the relations between directors and rapporteurs tended to be cordial. Most directors often consulted their rapporteurs and solicited their advice, because the latter, as recordkeeper, were more familiar with the volume than any other member on the committee. Given this role it is regretable that each volume does not identify its rapporteur.

While the subcomittee on organization was meeting, the committee itself discussed the layout and the contents of the work. There would be eight volumes of 30 chapters each, or 240 chapters in all. The number of chapters greatly exceeded the total number of historians of Africa then practicing. Therefore rules were laid down to limit to two the number of chapters per volume that would be entrusted to a single author. The committee explicitly counted on the contributions of young scholars who were then still in training. Unesco shared this stance, which explains why the agency did not appoint all 39 members of the committee at once. The committee also laid down a list of contents for each chapter in each volume. It since has stuck to the schema laid down in 1971, except in the case of volume 8. Hence the overall conception of volume 5, published in 1992, for instance, was planned twenty-one years earlier!

The committee then appointed directors and rapporteurs for seven volumes, but no one there could be found to undertake the last one. Given the criteria, the result was the choice of two North Africans, two East Africans (both from Kenya), and four West Africans. The fact that no one from Central or 
Southern Africa was appointed is a reflection of the near total absence of African historians from these regions at that time. At a later meeting a (European) associate director was appointed in the case of volume 3, because the advanced age of the director of this volume did not allow him to carry out all the tasks of a volume director vigorously.

The goals of the whole project were also laid out in detail. The GHA was to provide the history of Africa with a general work of reference so as to avoid the situation prevalent in Europe where competing and conflicting histories (e.g., France and Germany) have played a significant part in friction between citizens of different states. Given the importance of historical consciousness for national identities, the dissemination of the expected results in Africa was discussed. The main edition would come out in Arabic, English, and French. A shorter, cheaper paperback version for beginning university students was planned in the same three languages. Translations of these in African languages (Swahili, Hausa, perhaps others) was foreseen. These versions would then be used to write manuals for use in schools from K-12 and the eventual production of this version in comic strip form for the nearly illiterate was considered.

Given the importance of combating prejudice by disseminating a better knowledge of Africa to other continents, translations in non-African languages were welcomed, although Unesco would not organize these in any way. Still members of the committee maintained the right to check on such translations and they did so later, even for the Chinese version! Moreover, because African history was such a new field it was foreseen that where gaps occurred in the existing literature, where questions were controversial, or where tools for further research were urgently needed, Unesco was to organize special symposia. Eventually twelve symposia were convened and the results of eleven of them were published. Future historiographers should not overlook the impact these symposia had on the writing of the GHA itself.

\section{IV}

\section{Difficult Years: 1971-78}

The Paris meeting had proposed such ambitious plans and so unlike anything Unesco had ever attempted before that nearly all its officials remained extremely sceptical about the outcome. Their experience had been with works edited by one, two, or three scholars attached to prestigious western universities, in which Unesco merely provided a modest supporting role and perhaps raised some subsidies. Even those sympathetic to the endeavor were convinced that a general history of Africa could never emerge from such an arrangement, while many opposed the whole idea. ${ }^{12}$ Some internal hostility in Unesco had political roots. It was linked to the growing irritation with the agency of many of its most powerful member states. Great Britain, the Soviet Union, and the United States especially resented the growing weight of an 
Asiatic and African bloc that frequently outvoted them and this project was perceived as an illustration of that process. Among the major powers only France backed the agency, in part no doubt because it was based in Paris and French influence was strong within Unesco.

For a while the whole project was in danger of being scrapped. Then, however, Amadou-Mahtar M'bow, a Senegalese, was appointed as the new director general in 1974. He reacted to the situation a year later by nominating additional committee members from Brazil, the USA, Singapore, Trinidad and Tobago, and three African countries so that the major western countries were now well represented. Later, as vacancies occurred, replacements were procured from different countries but from the same world areas. While this countered some of the political misgivings, the hostility and incredulity within Unesco persisted and even grew when it appeared that committee work on the project was slowing down considerably, as it did between 1975 and 1978. Distrust at Unesco ebbed only after 1980 when the first volume was actually published.

The project was saved by the determination of the African member countries at every Unesco general conference, the stubbornness of $M$. Glele and the support of the director general of the agency. As more volumes were published disbelief within Unesco waned and finally turned to enthusiasm. By the middle 1980 s the project became so fashionable that it was used as a model for proposed 'general histories' elsewhere (e.g., the Caribbean, Central Asia).

Meanwhile the practical work began. The committee met as foreseen in 1973 (Lusaka), in 1975 (Cotonou), and, one year late, in 1978 (Nairobi). In addition the bureau met in the fall of 1971 (Cairo), in 1972 (Butare), in 1974 (Addis Ababa), in 1975 (Fes) and in 1977 (Paris). Enthusiasm naturally reigned at first, but then equally naturally it began to yield to weariness when the scope, the complexity, and the hard work involved in the project became apparent. The early experience of broken deadlines were especially pernicious, until a technique was perfected by Glele to pressure most authors into meeting their deadlines. At the same time this was the run-in period, when organizational diagrams had to be put into practice. The partners in the joint enterprise steeped respectively in bureaucratic and academic cultures had to adjust to each other's ways. The members, prodded by Glele, who could be fiery at times, learned to pay due attention to both practical detail and principles of management e.g., that who did what and when was crucial, that deadlines were vital, that legal issues were genuine, and that decisions once made had to be applied.

Glele learned that the project could not be run in a tidy bureaucratic fashion, but involved the deployment of all his considerable diplomatic skills. As to the committee, it had a mind of its own, and one that was not often swayed by the ease or the difficulty of achieving a desired goal. But both sides rapidly learned to work with each other. ${ }^{13}$ Both sides quickly realized that the greatest danger to the project stemmed from deadlines broken by authors. They learned that it was necessary to identify as quickly as possible authors who were indifferent to any kind of appeal or pressure to complete their texts and discard them. The sooner one identified such persons, the sooner a new author was chosen, the less overall delay occurred in the end. 
As the project started up, a number of new issues appeared during this period. These had to be settled before a productive routine could set in. They mainly concerned editing and volume directors. Happily enough, no problems arose concerning the selection of authors. Members of the committee proposed various candidacies and curricula vitae were circulated. Given the size and the diversity of the committee no single factor biased the selection of authors. Moreover, suitable authors for most of the chapters were rare: often the problem was to find a competent author for a given chapter, rather than to have to choose among a plethora of them. I do not remember any bitter internal debate about the choice of an author, but I do remember many a debate as to where in the world one could find someone qualified and willing to undertake the task.

Still at the Paris meeting in 1971 a strong conflict about the organization and contents of volume 2 made it clear that basic rules about what constituted valid grounds for adopting, rejecting, or altering proposed texts had to be developed from the start. The clash then opposed Sheikh Anta Diop (Sénégal) the then lonely but strong voice for Afrocentrism ${ }^{14}$ and G. Mokhtar (Egypt), an Egyptologist who was director of the volume. The main contribution that emerged from this clash could be called the principle of heterogeneity. In no case would uniformity of interpretation within a volume be imposed on anyone. In 1971 some viewed this as a compromise, but if so it was a happy one.

Later on most members of the committee felt that the great diversity in outlook and ideology between different chapters in every volume were in fact a precious asset to the GHA. Given the wide divergence of cultural, ideological, religious, and national backgrounds among the committee members themselves, the clash made it evident that objections based exclusively on any of these grounds could not be entertained. As long as the interpretation of any author was based on evidence commonly accepted as valid; based on all the evidence known to and relevant in the judgment of the committee; was not flatly contradicted by other known data, and contained no internal contradictions, the interpretation should stand. If an alternative and very different interpretation was at least equally compelling to members of the committee as in the case of Ancient Egypt, an editorial note would be added to that effect.

The solution worked but, as it happened, did not often have to be resorted to. Where it has been, this is readily apparent to readers. For instance just such a disagreement explains why chapter 6 in volume 3 dealing with Bantu expansion has two authors and its nature is explained in the editor's note following the chapter. This method of dealing with such issues failed only once. The disagreements between an author who shared H.N. Chittick's conviction that the cities on the East African coast were basically Asian, a view shared by two committee members and all the other committee members, who held them to be primarily African led to the withdrawal of this contribution and its replacement by a contribution of F.T. Masao and H.W. Mutoro. ${ }^{15}$ In this case all the members of the committee finally agreed that the Chittick position did not account for all the known archeological evidence.

It soon became apparent as well that in order to advance the project the directors of each volume should join bureau meetings whenever their volume 
was to be discussed. The major problem here was to find a director for the last volume, Africa Since 1935. No African historian could be found to direct volume 8. After years of searching the committee, at its wits end in 1976 or 1977, and discarding the relevant criteria, approached Ali Mazrui, despite the fact that he was not a historian, nor a member of the committee, and he was a citizen of Kenya, a country which already had a volume director. Mazrui accepted the charge, after which discussions about the content of that volume began. These pitted a political science approach against an historical one and they were concluded only after the meeting of Nairobi in 1978, and finalized in 1979.

\section{$\mathbf{V}$}

\section{Editing Routines: 1978-85}

Its teething problems settled, the project then took off. Despite the difficulties of the early days, actual work had been proceeding. From 1977 onwards, and the committee meeting at Nairobi in 1978, rapid progress was made. On the editorial side the most common problem remaining was that a submitted chapter covered only part of the area assigned, mainly because the author was not an expert on the other parts that needed to be covered. Often this simply resulted from the fact that the literature for one part of the chapter was predominantly in English and for the other in French. A supplementary author was then appointed and the contributions fused. Or a text could be accepted but needed to be reworked to a considerable extent by another author. Or again a text was rejected but some of its information was used by the next author so that the previous one had to be given credit. All these cases are reflected in the credit given. Among these chapters some have co-authors, others list "sections on X by," or "revised by," or "based on a contribution by" as appropriate. 16

A few attempts were made by member states of Unesco to put pressures on the committee either to impose a particular author or to alter a draft. They were all rebuffed. A few of these involved great powers, others African countries themselves. When pressured, Unesco invoked the autonomy of the committee, and referred diplomats to the bureau and its president, who foiled the few attempts made. The most annoying one turned out to be a minor feature: the correct geographic designation for "Persian" or "Arabian" Gulf in volume 5, page 130, map 5.2. Opposing views by delegates to Unesco from various countries about this issue could not be resolved for years and blocked the publication of volume five until 1992 !

Within the committee conflicts of this nature were extremely rare. Only the two members from the USSR and Libya ever attempted to act as a delegate of their countries and in each case the chair of the committee simply but firmly ruled them out of order. That is not to say that differences in national origin never played a role. They did so most often when members pointed out 
that the contribution of their part of Africa or of their country, or of another part of the world had been neglected or was misrepresented. Sometimes the case was conceded and the text was either reworked or a section added by another author to rectify the situation as happened, for instance, for chapter 15 of volume 6, which deals with Ethiopia and Somalia. But usually the case was dismissed and the text was maintained as it stood. Other conflicting positions based for instance on religion occurred once or twice, but were resolved in the same manner.

Most irritating to the committee were the unavoidable delays. Although most authors met their deadlines, some continued to throw off publication schedules, sometimes repeatedly. In the case of weak contributions new authors had to be sought, which again caused delays. And with every delay every other contribution became more out of date. In particular, the bureau did everything possible to cut the length of time it took between the acceptance of the first chapter and the last. Yet in time the whole enterprise fell more and more behind schedule. So the practice developed of asking members of the committee present at meetings to undertake the revision themselves there and then and, especially after 1983, more and more members were involved as coauthors, collaborators, or contributors in order to avoid having to search for new collaborators with further dangers of delays. At bureau meetings after 1983 members began - after discussion and following comments contained in the volume report-to write minor amendments themselves, so that the chapter could be finalized and sent by mail to the other committee members for approval.

Despite all this the delays remained considerable and readers must be aware of them. For instance I wrote chapter 3 for volume 5: it was accepted in 1978 and published essentially unchanged in 1992, fourteen years later. In another case $^{17}$ the text was approved in 1975 but appeared in 1985. By then major elements in the interpretation were out of date. In many cases such delays infuriated authors, who blamed the committee rather than the few individuals who were tardy or never delivered their promised work. As a consequence of these delays, however, historiographers cannot rely on the date of publication of each volume as reflecting the opinion of the times. They will need to research the dates of final acceptance for every chapter. ${ }^{18}$

Although such frustrating delays occurred with all volumes, volume 8 , which dealt with the period 1935 to 'now' was delayed by other problems. Authors could be approached and given contracts only after 1979 because the contents of the volume had been agreed on only in that year. Problems with finding appropriate authors dragged on for years. Moreover, Ali Mazrui was overwhelmed by other demands on his time and was not as involved as other volume directors had been. Therefore in 1984 the committee appointed C. Wondji as co-director, hoping that this step would allow the volume to be completed rapidly. Wondji is a historian from the Ivory Coast by training and a diplomat by profession. The fact that he uses French as a working language was seen as an apt complement to Mazrui's background, but Wondji was also overcommitted and the pace of volume 8 did not accelerate. 


\section{Other Issues, 1978-85}

Publication issues were the most central among the other problems facing the project. The structural difficulty consisted in the fact that Unesco was responsible for publication, yet the committee felt that the agency should not have a free hand in this matter. Where items were published, by whom, and at what price inevitably determines access to the GHA and the committee did not want to relinquish a voice in this issue. For its part, the agency had to convince publishers to embark on the major endeavor of bringing out eight large volumes, with a full scholarly apparatus and many maps and illustrations (some 125 for Volume 5 alone) and to find such publishers for each of the three languages of the original edition. Moreover, Unesco had to translate all the texts into them. The bilingual or trilingual members of the committee then read, criticized and finally approved the translations. The committee also insisted on a low sales price to render the books affordable and repeatedly introduced proposals for a better distribution system in Africa. It also insisted on banning both elitist 'deluxe' editions, ahead of the general edition, and the publication of the shortened paperbacks until five years after the publication of the volumes of the general edition. Unesco found a satisfactory arrangement with publishers for the English language edition, but not for the others.

The Arabic-language edition was delayed mainly by the difficulty of finding large publishing houses with academic experience in the Middle East. The practices of publishers in France being what they are, the publication of the French language edition became an ordeal and the difficulties are still not resolved..$^{19}$ The short versions in Swahili and Hausa posed even larger problems. Because large-scale academic publication had not been hitherto attempted in either language, special problems of translation and standardization had to be gradually solved by committees of specialists. But now the first volumes are finally ready.

Meanwhile the ancillary projects accompanying the writing of the general history of Africa were also proceeding apace and with surprisingly little friction. The guides to archives were being published and symposia on special issues relating to the project were regularly requested by the committee. Eleven of these took place between 1974 and 1984. and Unesco published the proceedings as General History of Africa: Studies and Documents. The first one was the symposium on Meroitic held in 1974 in Cairo. Later symposia dealt with the Atlantic slave trade, historical relations across the Indian Ocean,the historiography of southern Africa, decolonization in the horn of Africa, African ethnonyms and toponyms, relations between Africa and the Arab world since 1935, the methodology of contemporary Africa, education and historiography in Africa, Africa and the second World War, and the Saharan lands in antiquity (Paris 1988 Lybia antiqua). As noted, historiographers should not overlook the impact of these symposia on the field. They were public discussions, often 
about disputed issues whose results were often available years before they made their impact on GHA itself.

Nor should the historiographer overlook the impact of the committee and the bureau on the teaching of history at African universities. At every meeting held in Africa, members discussed the project and issues with historians at the local universities or colleges, assessed local knowledge about the history of Africa, and inquired about the contents of textbooks. They held talks for the general public and spoke on the local media to explain the importance of historical consciousness and the need to break away from colonial legacies in this respect. In a more general way such meetings in Africa directly strengthened the support of African governments towards historical research, because the message of the committee was backed both by the prestige of Unesco in Africa and by the locally-recognized eminence of some of its members.

Indeed, even a glance at the list of the members of the committee and of the successive bureaus shows that many among them have attained eminence as leading intellectuals in their countries within academic life, and in not a few cases in political life as well. Neither the committee nor its bureaus ever were ivory towers. Rather they were strongly affected by the general tides of intellectual life and political aspirations both in Africa and outside it.

What can be labeled the Diogenes affair should be seen in this context. We were all aware that in certain quarters of Unesco active resistance to the whole idea that Africa's past was important for humanity was still virulent, but we were still surprised when Diogenes, a journal published by Unesco, carried an article by Cyril Hromnik in 1982, ${ }^{20}$ in which he argued that Indians with a superior civilization were responsible for whatever worthwhile achievements one could find in southern and eastern Africa. The committee was up in arms. Hromnik was a known campaigner for apartheid and suspected of being a propaganda agent of the South African government. That such blatant racism could appear in a journal published by Unesco outraged the committee. It instructed some of its members to draft a refutation and demanded a right of reply. At first the editor of Diogenes refused, but four years later he finally published the refutation. ${ }^{21}$

Future historiographers will not believe that every member of the committee and of the bureau contributed in equal measure to the whole project. Indeed they did not. After the first enthusiasm waned many committee members tended to leave most of the work to the bureau and confined themselves to restricting their own contributions to questions well within their expertise. The future historiographer will be able to follow everyone's contribution by consulting the reports and the correspondence for each volume. But that is not unusual. The remarkable feature of the organization is that so many scholarsthe members of the bureaus, the directors of volumes, and certain committee members-actively participated during nearly twenty years in the work of the project. Such lively academic discussions occurred at some meetings that Unesco observers compared them to university seminars and sometimes complained because such discussions seemed to hold up decision-making. 
Meanwhile an esprit de corps gradually developed outside the formal meeting rooms. In 1971 most members did not know each other, but in time mutual respect grew and friendships ripened among those who were most involved in the project. A single seamless pool of friends did not develop, however, if only because there were genuine difficulties of communication between French- and English-speaking members of the committee, accompanied by differences in academic culture. ${ }^{22}$ But there were enough thoroughly bilingual members to keep participation in such discussion groups fluid. And so after work, there were lively discussions, often until late in the night, about issues of African history; the conditions for intellectual life in Africa; and about such general topics as racism, the situation and the future of ideologies, economies, politics, or social life in various parts of Africa and elsewhere. As a result everyone's understanding of what was currently going on in Africa deepened. In this way as well, members not only kept abreast of the general currents of contemporary thought, but were influenced by them in evaluating the quality of chapters submitted to the GHA.

\section{VII}

\section{The Final Years, 1985-93}

By 1985 the project was well on the way to completion. Most of the volumes were published or had been approved by the committee. True, there were continuing problems of publication in languages other than English, and volume 8 was only half done, but one could foresee the end. It was projected that by 1988 all the volumes would be out. Then a final general meeting could be held in 1989 to assess the whole program. Younger historians who had not been involved with the project would evaluate it, plans for revisions would be made, and new structures devised to bring the gist of the history into textbooks for schools and to the general public in Africa. Such was the mood of confidence among the committee members in 1985 that they decided that the remaining task could easily be completed by correspondence and that no general meeting of the committee needed to be called before the final one.

But that confidence in the future was misplaced because Unesco had entered into a general and fiscal crisis beginning in $1984 .{ }^{23}$ At first this did not directly affect this project because its finances were in a separate account, but it created a distinct malaise in the agency. Later major shifts in Unesco personnel had a decisive impact on the future of the project. In 1987 A. M. M'Bow was replaced as director general, in $1989 \mathrm{M}$. Glele was promoted to higher office and left the project to A. Gatera, while later in 1989 illness forced J. Devisse to restrict his activity as general rapporteur. By 1991 the secretariat of the project had become insignificant and rumor had it that its accounts had been transferred to the service of publications.

As to work on the project itself, the delays and complications for volume 8 dragged on interminably, and even the bureau meetings of 1987 and 1989 
could not speed the process up much. In the autumn of that year the bureau could only note that volume 8 was not ready. Meanwhile the agenda of that year primarily dealt with the project of turning the main edition into a set of three handbooks for high schools. Unesco then decided not to call any more meetings of the bureau until volume eight was published and the project completed. The intractable problems of volume 8 were by now inducing a growing lassitude among most members of the committee, to the point that they no longer reacted quickly to proposed versions for various chapters. In the end the last chapter was only finally approved in 1991 and the volume will-perhaps-be published in 1993. In 1992 committee members were told that their last meeting was now scheduled for 1993 and would be considerably scaled down from the plans made in 1985. Thus it looks as if one of Unesco's most ambitious and successful intellectual projects will end not with a bang but with a whimper.

\section{Excursus}

The project has generated a huge number of papers and tapes, most of which are housed at Unesco in Paris. The records are still in use and hence inaccessible at this time. Among the documents the following five major classes can be distinguished:

1/ In-house materials, dealing with internal matters, correspondence with member states of Unesco concerning a variety of issues (appointments to memberships, venues of meetings, diplomatic notes), and reports about the biannual general conference of member countries.

2/ Financial and legal records such as contracts for all aspects of the project, annual budgets, expense accounts, and gifts by member countries.

3/ General relations with the committee. This includes minutes of all the meetings of bureau and committees, tapes (and transcripts?) for many of these meetings, statements made by the Unesco secretariat, matters of venue for meetings, correspondence with the presidents of the committee and the general rapporteur, notes about visits by members of the committee to the secretariat, and direct correspondence between members and the secratariat.

4/ On the project itself and per-volume correspondence with the directors of volumes and with authors, copies of all drafts and all comments about all chapters in the work, including the reports by the rapporteur for each volume, all data relating to publishing (from production through distribution), data about abridged versions and translations. The eight categories in this section form the bulk of the archival record. 
5/ Records about the ancillary projects, e.g., the publication of guides, the symposia, the conferences concerning translations in Hausa and Swahili, other conferences subsidized in part by the program, translations in other languages, plans for educational adaptations of GHA for schools, etc.

6/ Issues of public relations such as advertising, notes about the reception of the project, book reviews, and reactions from the reading public.

But Unesco does not hold all the records about the project. For instance a portion at least of the correspondence between directors and authors, direct correspondence between members of the committee or bureau, and correspondence between any one of these and potential authors or referees can be found only among the papers of the various members of the committee. Every member of the bureau and of the committee received information concerning meetings, agendas, and minutes of all meetings; all drafts of chapters; all comments about every chapter; rapporteur reports for each volume; and all data concerning abridged volumes. Moreover, many members kept notes about discussions at meetings which they attended. Many also corresponded with some or all the authors outside the formal framework of Unesco and sometimes with other members. In addition to all this, directors of volumes also held records issuing from their own contacts with authors and with the Unesco secretariat. It is hardly likely that any member of the project kept all the documents received, but everyone may well have kept the papers which interested them most.

Eventually the Unesco records should become accessible to the public and one hopes that many of the participants in the project will deposit their papers in a public repository as well. For the record of this unique venture in twentieth-century historiography may well be the most informative and varied single source about the history of African history between ca.1965 and 1990 anywhere. It contains the makings for solid quantitative assessments (e.g., the number of practicing African historians in the world at various times) as well as for detailed qualitative studies (e.g., correspondence, comments, and successive drafts of every chapter) concerning the respective impact of the various schools of thought then active in most of the world, as well as the influence of personalities, contemporary events, and...sheer serendipity!

With regard to African history, to my mind at least, GHA has been the most impressive venture of this century, not only because of its size or complexity, but because it involved authors from the most diverse origins and belonging to all the schools of thought then active in international academic circles.

\section{Notes}

1. UNESCO, eds. General History of Africa, London, Berkeley, Paris 1980 to 1992, seven volumes (volume 8 due in 1993); Roland Oliver, John D. Fage, The Cambridge History of Africa, Cambridge 1975-1986, eight volumes. This account is clearly affected by my own involvement in the UNESCO venture. 
2. While it is too soon to write a history of the project, it is time at least to outline its activities and draw attention to the records generated by the project. My own papers concerning this total around 10,000 pages and are being deposited at the Memorial Library of the University of Wisconsin in Madison.

3. Paris, where Présence africaine was published, was then the focal point for international discussions about African cultures and the journal captures that intellectual climate well.

4. So far eight volumes have been published under the aegis of the international Council on Archives, beginning with volume 1 (Germany) in 1970. Among repositories of major interest to African historians, the guides to the Portuguese and Turkish archives are still not published, while come countries, like the United Kingdom and the Netherlands, have published their guides separately. For UNESCO's involvement see the preface by A.M. M'Bow in GHA, 11 (French edition).

5. CHA 4 (1975): xi-xii. The CHA project was well ahead. A first volume was published in 1975 as against UNESCO's first volume in 1980.

6. GHA 1, 787-88 (French edition) gives their names. Later volumes give updates. For the final list see GHA 5, 1992 (English edition). For the rules guiding the composition of the committee A. M. M'Bow, GHA 1, 1980: 11 (French edition).

7. A general description of the project, including its procedures and its ancillary projects can be found in UNESCO, Preparation of a General History of Africa, Paris 1983, 32.

8. The personal interest of A. M. M'Bow, Director General of UNESCO from 1974 to 1987, and a citizen of Sénégal, has clearly been significant in this relationship.

9. To my knowledge this occurred only once in the whole project.

10. Illustrations were in theory to be provided by authors and to be approved by the committee. In practice a volume was often approved when only a portion of the relevant illustrations had been accepted. Hence the role of the director became more important than had been foreseen. In contrast the cover illustrations for each volume were discussed at length and on several occasions by the committee because of their symbolic importance for the project as a whole.

11. In most cases committee members did not spend much time on this verification, although the committee rejected the version provided by the director of volume 4 and entrusted the task to the director of volume 1 .

12. Beginning in 1950 UNESCO sponsored The History of Mankind, which would be comprised of many volumes. But thirteen years later only J. Hawkes, Prehistory, and Leonard Woolley, The Beginnings of Civilization (1/1-2) had been published. The fate of this muchheralded project helps to explain why scepticism reigned at the agency. Moreover, two major differences between the GHA and this project are instructive in this regard. First, the volumes for this project were actually written by single people. If a project involving so few authors did not succceed, how could one hope better for one involving over 200 authors? Secondly, the spirit in which The History of Mankind was planned was that of the Journal of World History. The notion of elite 'civilizations,' as distinct from plebeian 'cultures,' was central to its endeavor. Indeed, for Woolley "the Beginnings of Civilization" still was to be found only in the Middle East! The whole venture was imbued with ethnocentricity, yet many UNESCO officials personally believed in such views, even as late as the 1970s, which explains their arrogant animosity towards the GHA project.

13. This process was perhaps accelerated by the fact that many committee members, including most members of the various bureaus, had acquired or were acquiring considerable administrative experience during their own careers, usually in managing universities or in political life.

14. Sheikh Anta Diop, Nations nègres et culture (Paris, 1955), and his later Antériorité des civilisations nègres: Mythe ou vérité historique (Paris, 1967).

15. GHA 3, 1988: 586-615 (English edition).

16. For instance: GHA 7, chapters $4,6,8,11,13,17,27,28,29$.

17. GHA 7, chapter 8 .

18. A feeling for the delays involved can be gathered by comparing the various editons of UNESCO, Preparation of a General History of Afirca. The order of volume publication from 
1980 to 1992 is $1,2,4,7,3,6,5$, and 8 . As a result differences between chapters in one volume and between volumes-reflect different approaches contemporary to each other, but also the changing intellectual climate of history over a twenty-year timespan.

19. With regard to the publishers of the French edition it is instructive to note who published which volume of the costly main edition and who published which volume of the lucrative shorter paperback version.

20. C. A. Hromnik, "Recent Models for the African Iron Age and the Cattle-Related Evidence," Diogense 119 (1982), 103-13. Cf. also his Indo-Africa: Towards a New Understanding of the History of Sub-saharan Africa (Cape Town, 1981). For the spirit of animosity which reigned at Diogenes see note 12 .

21. The Committee's reply was published as "Concerning the Article by Cyril A. Hromnik," Diogenes 135 (1986), 131-39.

22. Various styles of academic culture were easily noticeable in the discussions. Most obvious was the understated and down-to-earth English-speaking style contrasted with a more discursive French thetoric, but committee members soon learned to recognize several other styles of presentation and eloquence. But the commonality of the international academic culture, fostering a common sense of historical consciousness is even more relevant. Had not all the members of the committees shared this common approach, the project would have failed.

23. For accounts of this crisis see Clare Wells, The UN, UNESCO, and the Politics of Knowledge (London, 1987), and S. Nihal Singh, The Rise and Fall of UNESCO (Ahmedabad, 1988). 